\title{
Comparative evaluation of apical constriction position in incisor and molar teeth: An in vitro study
}

\author{
Seyed Amir Mousavi ${ }^{1}$, Alireza Farhad ${ }^{1}$, Shirin Shahnaseri ${ }^{2}$, Abbas Basiri $^{1}$, \\ Erfan Kolahdouzan ${ }^{3}$
}

Correspondence: Dr. Shirin Shahnaseri

Email: shahnaseri@dnt.mui.ac.ir

\begin{abstract}
'Department of Endodontics, Dental Research Center, School of Dentistry, Isfahan University of Medical Science, Isfahan, Iran,

${ }^{2}$ Department of Oral and Maxillofacial Surgery, Dental Implant Research Center, School of Dentistry, Isfahan University of Medical Science, Isfahan, Iran,

${ }^{3}$ Dental Student Research Center, School of Dentistry, Isfahan University of Medical Sciences, Isfahan, Iran
\end{abstract}

\section{ABSTRACT}

Objective: The apical constriction (AC) and the apical foramen (AF) are the principal reference points used to determine the apical limit for instrumentation and root canal filling. AC varies in different races, and the aim of the current study was to measure and compare the distances from $\mathrm{AC}$ to $\mathrm{AF}$ and the anatomical apex (AA) in incisor and molar teeth in the Iranian population. Materials and Methods: Forty-five roots of incisor teeth and 45 roots of molar teeth were selected randomly in Isfahan Province, Iran. If the foramen was located toward the mesial or distal side of the apex, the cut was made mesiodistally, and if it was toward the buccal or lingual side, the section was made accordingly. Roots were examined under a microscope at $\times 25$ magnification. The distances from AC to AF and AA were then estimated using a Motic camera. Descriptive statistics were used. The independent $t$-test was also used to compare distances in incisors and molars, and $P=0.05$ was deemed to indicate statistical significance. Results: The mean distances between AC and AF were $0.847 \pm 0.33 \mathrm{~mm}$ in incisors and $0.709 \pm 0.27 \mathrm{~mm}$ in molars. The mean distances between AC and AA were $1.23 \pm 0.39 \mathrm{~mm}$ in incisors and $1.01 \pm 0.38 \mathrm{~mm}$ in molars. In an independent $t$-test, the distances between AC and AF differed significantly in incisors and molars $(P=0.035)$, but the distances between AC and AA did not $(P=0.172)$. Conclusion: The end points for root canal therapy should be $0.85 \mathrm{~mm}$ in incisors and $0.70 \mathrm{~mm}$ in molars.

Key words: Anatomical apex, apical constriction, apical foramen

\section{INTRODUCTION}

Biomechanical cleaning of the pulp chamber and preparation of a root canal system are mandatory steps when aiming to achieve long-term success in root canal therapy. Insufficient cleaning and shaping of the apical zone usually lead to infected tissue and debris remaining in the canal. These undesirable residues

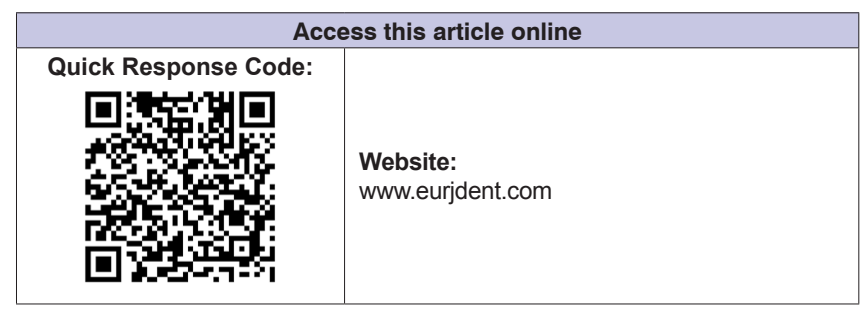

in the apical area can lead the resistance of periapical lesions and root canal therapy failure. ${ }^{[1]}$

In normal root canals, the apical constriction (AC) is considered the narrowest and more apical area

This is an open access journal, and articles are distributed under the terms of the Creative Commons Attribution-NonCommercial-ShareAlike 4.0 License, which allows others to remix, tweak, and build upon the work non-commercially, as long as appropriate credit is given and the new creations are licensed under the identical terms.

For reprints contact: reprints@medknow.com

How to cite this article: Mousavi SA, Farhad A, Shahnaseri S, Basiri A, Kolahdouzan E. Comparative evaluation of apical constriction position in incisor and molar teeth: An in vitro study. Eur J Dent 2018;12:237-41.

DOI: 10.4103/ejd.ejd_54_18 
to the apex. From AC or minor apical diameter, the canal widens as it approaches the apical foramen (AF) or major apical diameter. ${ }^{[2]}$ The main path between pulp tissue and periodontal tissue is through the apical and lateral foramen. Treatment is only likely to be successful when the entire path of the root has been cleaned and shaped in accordance with a predetermined precise working length (WL). ${ }^{[3]}$

The exact location of the reference point and obturation can affect the results. By studying preradicular tissue, researchers have concluded that the best prognosis is achieved when root canal treatment terminates at the cementodentinal junction (CDJ). ${ }^{[4]}$ Although the exact location of $\mathrm{CDJ}$ is immeasurable, $\mathrm{AC}$ is an appropriate and reliable location as the terminus of root canal procedures. ${ }^{[4]}$

New methods of measuring WL such as electronic apex locators can locate CDJ, and thus, it can be used as the termination point of procedures. ${ }^{[5]}$ All modern canal preparation techniques aim to differentiate between the canal and apical tissue. ${ }^{[6]} \mathrm{AF}$ does not normally exit at the anatomical apex (AA), but it is laterally offset $0.5-2.0 \mathrm{~mm}$ in the coronal of AA. ${ }^{[2]}$ Conditions such as aging and root resorption can affect the position of $\mathrm{AC}$, for example, aging and cementum apposition in the apical area cause increased space between $\mathrm{AC}$ and $\mathrm{AF}{ }^{\left[{ }^{[3]}\right.}$ $\mathrm{AC}$ can be a simple constriction, tapering constriction, multiple constriction, or parallel constriction, and in a few cases, it is filled with restorative dentin or cementum. ${ }^{[6]}$ Various methods have been used to study root canal morphology, including tooth decalcification, staining and clearing techniques, root sectioning and radiographic examination (in vitro), ${ }^{[7]}$ alternative radiographic techniques, ${ }^{[8]}$ and evaluation with contrast media. ${ }^{[9]}$

Modern radiographic techniques such as spiral computed tomography and micro-computed tomography are very useful. ${ }^{[10,11]}$ Despite the accuracy of these modern techniques, they require expensive equipment. ${ }^{[12]}$ In view of the importance of the precise $\mathrm{WL}^{[4]}$ and variable root canal systems in different races $^{[13,14]}$ and the difference between incisors and molars, ${ }^{[15,16]}$ the current study attempted to determine the distances from $\mathrm{AC}$ to $\mathrm{AF}$ and $\mathrm{AA}$ and compare the mean distances in incisors and molars.

\section{MATERIALS AND METHODS}

In this cross-sectional study, 90 teeth including 45 incisors (single-rooted tooth) and 45 molars (multi-rooted tooth) that had been gathered from personal offices, clinics, and the dental faculty of Isfahan Province, Iran, were used. The results of a pilot study were used to determine the sample size. In the pilot study, the difference between AC and AA in both incisors and molars was $0.1 \mathrm{~mm}$, with a standard deviation of $0.25 \mathrm{~mm}$. Incorporating $\alpha=0.05$ and $80 \%$ power of the final sample size, 90 teeth were used in the current study.

No information about the age or sex of the tooth donors was available. All the teeth included had a reasonably intact crown and a relatively complete root - specifically a well-formed apex without any resorption or fracture. The reasons for tooth extraction were periodontal disease or orthodontic treatment. Classification of the teeth as incisors or molars was performed separately by endodontics experts, through Woelfel's standard. Only teeth selected by both experts were used in this study. The teeth selected were cleared of any soft tissue, bone fractions, and mass through manual scaling. For disinfection, the teeth were then put in $2.5 \% \mathrm{NaOCl}$ (Orkyd, Tehran, Iran) for 2 days, washed with running water for $4 \mathrm{~h}$, and floated in 10\% formalin (Pars Chemistry, Tehran, Iran) before analysis.

To determine the position of $\mathrm{AC}$, the following procedures were performed:

First, the crown of each tooth was sectioned using a diamond bur ( $\mathrm{D}+\mathrm{Z}$, Frankfurt, Germany) to expose the root canal system. It was then rinsed with $2.5 \% \mathrm{NaOCl}$. The side where AF emerged was visualized by means of a stereoscopic magnifying glass (Citoval 2; Carl Zeiss, Germany). This allowed the roots to be oriented in such a way that the longitudinal sections were possible. If the foramen was located somewhat toward the mesial or distal side of the apex, the cut was made mesiodistally. If it was toward the buccal or lingual side, the section was made accordingly. If there were two foramens, the section was made on the same plane to enclose both of them. Root sections were divided with a modeling spatula (Schuler, Ulm, Germany). Sectioned roots were observed through a stereomicroscope (Hp, California, USA) with a magnification of $\times 25$, and the distances from $\mathrm{AC}$ to $\mathrm{AF}$ and $\mathrm{AA}$ were measured through a digital camera (Motic Instruments Inc., California, USA) and Motic Images Plus software (Motic instruments Inc.). Microscopy images of $\mathrm{AC}$ and $\mathrm{AF}$ in the molar tooth root apex are shown in Figure 1, and corresponding images derived from incisors are shown in Figure 2. 


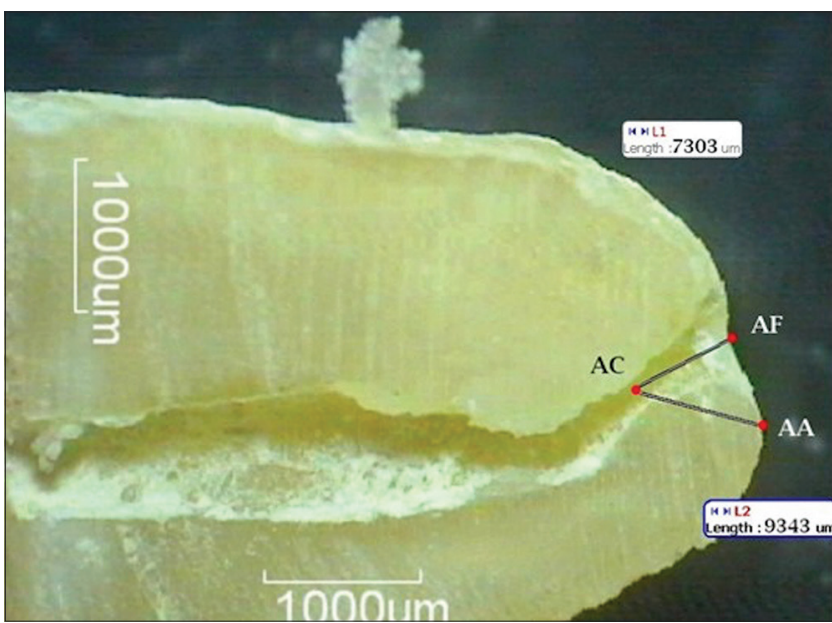

Figure 1: Microscopic view of molar root tooth apex, apical constriction, apical foramen, and anatomical apex

Mean distances from $\mathrm{AC}$ to $\mathrm{AF}$ and $\mathrm{AA}$ and associated standard deviations were calculated and recorded, and data were analyzed with Statistical Package for the Social Sciences 22, SPSS( IBM, NY, USA). The independent $t$-test was used to compare the distances measured, and $P<0.05$ was deemed to indicate statistical significance.

\section{RESULTS}

The mean distances between $\mathrm{AC}$ and $\mathrm{AF}$ were $0.84 \pm 0.33 \mathrm{~mm}$ in incisors and $0.70 \pm 0.27 \mathrm{~mm}$ in molars [Table 1]. The mean distances between AC and AA were $1.123 \pm 0.389 \mathrm{~mm}$ in incisors and $1.010 \pm 0.384 \mathrm{~mm}$ in molars [Table 2]. The mean distances between $\mathrm{AC}$ and $\mathrm{AF}$ differed significantly in incisors and molars $(P=0.035)$, but the mean distances between $\mathrm{AC}$ and AA did not $(P=0.172)$.

\section{DISCUSSION}

One of the important goals of endodontic treatment is biomechanical cleaning of the root canal system. This biomechanical cleaning involves mechanical removal and chemical dissolution and neutralizes content of the canal, while the primary aims of canal preparation include due determination of obligate canal geometrics for adequate obturation without any extension beyond the apical region. AC is an appropriate terminus location in root canal therapy. ${ }^{[4]}$

Few studies have investigated AC in Iranians; hence, determining the distances between $\mathrm{AC}$ and $\mathrm{AF}$ and $\mathrm{AA}$ in this race is important. Dummer et al. ${ }^{[6]}$ investigated the apical anatomy of central and lateral incisors, canines, and premolars. On average, AC was $0.89 \mathrm{~mm}$ coronal to AA.

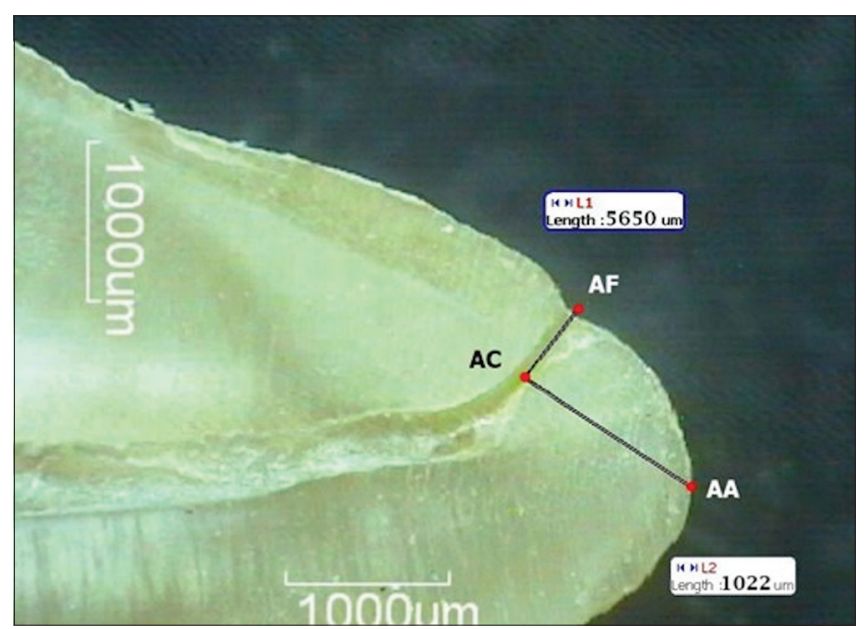

Figure 2: Microscopic view of incisor root tooth apex, apical constriction, apical foramen, and anatomical apex

Table 1: Distance between apical constriction and
apical foramen $(\mathrm{mm})$
\begin{tabular}{|lccc}
\hline Tooth type & Average & Standard deviation & $\boldsymbol{P}$ \\
\hline Incisor & 0.847 & 0.330 & 0.035 \\
Molar & 0.709 & 0.278 & \\
\hline
\end{tabular}

Table 2: Distance between apical constriction and anatomical apex $(\mathrm{mm})$

\begin{tabular}{lccc}
\hline Tooth type & Average & Standard deviation & $\boldsymbol{P}$ \\
\hline Incisor & 1.123 & 0.369 & 0.172 \\
Molar & 1.010 & 0.384 & \\
\hline
\end{tabular}

Arora and Tewari ${ }^{[17]}$ reported that this distance was $0.63-0.99 \mathrm{~mm}$ in posterior multi-rooted teeth. Nasseri et al. ${ }^{[18]}$ reported a $0.9 \mathrm{~mm}$ distance between AA and AC. Marroquín et al. ${ }^{[19]}$ reported that AC was $0.86 \mathrm{~mm}$ from AA in mandibular molars and $1.00 \mathrm{~mm}$ from it in maxillary molars [Table 3]. In the current study, the mean distances between AC and AA were $1.14 \mathrm{~mm}$ in single-rooted teeth and $1.03 \mathrm{~mm}$ in multi-rooted teeth. Kuttler ${ }^{[3]}$ reported that the mean distance from AC to AF was $524 \mu$ in a group aged 18-25 years and that it was $659 \mu$ in a group aged over 55 years. Stein and Corcoran $^{[20]}$ reported a $0.91 \mathrm{~mm}$ distance [Table 3]. In the current study, the mean distances between $\mathrm{AC}$ and AF were $0.86 \mathrm{~mm}$ in single-rooted teeth and $0.72 \mathrm{~mm}$ in multi-rooted teeth. The results were concordant with the aforementioned previous studies. Piasecki et al. ${ }^{[21]}$ investigated single-rooted premolars, and the $0.59 \mathrm{~mm}$ distance they reported from $\mathrm{AC}$ to $\mathrm{AF}$ is not similar to the corresponding observations in the present study. The smaller sample size in Piasecki et al. ${ }^{[21]}$ and the more accurate measurement tool used in the current study may have contributed to the discrepancy between the two studies. Notably, 
Mousavi, et al.: Comparison of apical constriction position

\begin{tabular}{|c|c|c|c|c|}
\hline Researchers & Year & Studied tooth & Studied distance & Measured distance \\
\hline Piasecki & 2016 & Single-rooted premolar & $\mathrm{AC}$ to $\mathrm{AF}$ & $0.59 \mathrm{~mm}$ \\
\hline Nasseri et al. & 2012 & Second maxillary premolar & $A A$ to $A C$ & $0.9 \mathrm{~mm}$ \\
\hline Arora and Tewari & 2009 & Posterior teeth & $A A$ to $A C$ & $0.63-0.99 \mathrm{~mm}$ \\
\hline Hassanien et al. & 2008 & Mandibular premolar & $A C$ to $A F$ & $1.2 \mathrm{~mm}$ \\
\hline Marroquín et al. & 2004 & Molar teeth & $A A$ to $A C$ & $0.86-0.1 \mathrm{~mm}$ \\
\hline Stein et al. & 1991 & Not mentioned & $A C$ to $A F$ & $0.91 \mathrm{~mm}$ \\
\hline Dummer et al. & 1984 & Central, lateral, canine and premolar & $A A$ to $A C$ & $0.89 \mathrm{~mm}$ \\
\hline Kuttler & 1955 & Anterior and posterior teeth & $\mathrm{AC}$ to $\mathrm{AF}$ & $\begin{array}{c}524 \mu \text { (18-25-year-old) } \\
659 \mu \text { (over 55-year-old) }\end{array}$ \\
\hline
\end{tabular}

AC: Apical constriction, AF: Apical foramen, AA: Anatomical apex

Hassanien et al. ${ }^{[22]}$ reported an average distance of $1.2 \mathrm{~mm}$ between AC and AF in mandibular premolar teeth - a greater distance than has been reported in previous studies and in the current study - which may also be related to the precision of the method they used and the lower number of samples.

In the current study, the distances from $\mathrm{AC}$ to $\mathrm{AF}$ differed significantly in single-rooted and multi-rooted teeth. This may be due to a difference in root diameter size between these teeth in the apical third; nevertheless, there was no corresponding significant difference in the mean distance from AC to AA. Although $\mathrm{AC}$ is often considered the terminus of obturation ${ }^{[4]}$ and Electronic Apex Locators can show this region as the termination point of obturation, ${ }^{[23]}$ some clinicians obturate based on the radiographic apex. As the apical termination of obturation does not differ significantly between single-rooted and multi-rooted teeth despite vital and necrotic teeth, clinician judgment should not affect which based on radiography.

The current study was rendered more precise than some of the aforementioned studies by the use of modern observation and measurement tools such as a digital camera and the Motic Images Plus software. Furthermore, vertical root sectioning facilitated informative observation and measurement of different parts of the apex, whereas previous studies have used radiographic, tooth decalcification, and staining techniques that preclude direct observation.

One of the limitations of the current study relates to evolutional tooth age. With aging, cementum absorption in the apex zone and the distance from AC to $\mathrm{AF}$ increase. Although the age of root formation is an important source of variation and incisor growth is faster than molar growth, it is not practically possible to source enough teeth of the same developmental age to perform a meaningful study. Another issue pertains to the anatomic variation in root canal systems. ${ }^{[13,14]}$ Teeth were sourced from five provinces in Iran. A bigger sample size would have been preferable to reduce the potential effects of these variations.

\section{CONCLUSION}

The mean distances from $\mathrm{AC}$ to $\mathrm{AF}$ were $0.84 \mathrm{~mm}$ in incisors and $0.70 \mathrm{~mm}$ in molars. Since the prognosis is better when AC is considered the termination point of treatment, the terminus points should be $0.84 \mathrm{~mm}$ more coronal than $\mathrm{AF}$ in incisors and $0.70 \mathrm{~mm}$ more coronal in molars and $1.12 \mathrm{~mm}$ and $1.01 \mathrm{~mm}$ shorter than AA, respectively.

\section{Financial support and sponsorship \\ Nil.}

\section{Conflicts of interest}

There are no conflicts of interest.

\section{REFERENCES}

1. Vertucci FJ, Haddix JE, Britto LR. Tooth morphology and access cavity preparation. In: Cohen S, Hargreaves KM, editors. Pathways of the Pulp. $9^{\text {th }}$ edition. St Louis, Mo, USA: Mosby; 2006. pp. 148-232

2. Peters O, Koka R. Preparation of coronal and radicular spaces. Endodontics. $6^{\text {th }}$ ed. Hamilton, Canada: BC Decker Inc.; 2008. p. 877-991.

3. Kuttler Y. Microscopic investigation of root apexes. J Am Dent Assoc 1955;50:544-52.

4. Peters OA. Current challenges and concepts in the preparation of root canal systems: A review. J Endod 2004;30:559-67.

5. Ravanshad S, Adl A, Anvar J. Effect of working length measurement by electronic apex locator or radiography on the adequacy of final working length: A randomized clinical trial. J Endod 2010;36:1753-6.

6. Dummer PM, McGinn JH, Rees DG. The position and topography of the apical canal constriction and apical foramen. Int Endod J 1984;17:192-8.

7. Pineda F, Kuttler Y. Mesiodistal and buccolingual roentgenographic investigation of 7,275 root canals. Oral Surg Oral Med Oral Pathol 1972;33:101-10.

8. Levy AB, Glatt L. Deviation of the apical foramen from the radiographic apex. J N J State Dent Soc 1970;41:12-3.

9. Scarfe WC, Fana CR Jr., Farman AG. Radiographic detection of accessory/lateral canals: Use of RadioVisioGraphy and Hypaque. J Endod 1995;21:185-90.

10. Plotino G, Grande NM, Pecci R, Bedini R, Pameijer CH, Somma F, et al. 
Three-dimensional imaging using microcomputed tomography for studying tooth macromorphology. J Am Dent Assoc 2006;137:1555-61.

11. Sberna MT, Rizzo G, Zacchi E, Capparè P, Rubinacci A. A preliminary study of the use of peripheral quantitative computed tomography for investigating root canal anatomy. Int Endod J 2009;42:66-75.

12. Boruah LC, Bhuyan AC. Morphologic characteristics of root canal of mandibular incisors in North-East Indian population: An in vitro study. J Conserv Dent 2011;14:346-50.

13. Sert S, Bayirli GS. Evaluation of the root canal configurations of the mandibular and maxillary permanent teeth by gender in the Turkish population. J Endod 2004;30:391-8.

14. Cleghorn BM, Christie WH, Dong CC. Root and root canal morphology of the human permanent maxillary first molar: A literature review. J Endod 2006;32:813-21.

15. Tilk MA, Lommel TJ, Gerstein H. A study of mandibular and maxillary root widths to determine dowel size. J Endod 1979;5:79-82.

16. Woelfel JB, Scheid RC, editors. Basic terminology for understanding tooth morphology. In: Dental Anatomy: Its Relevance to Dentistry. $5^{\text {th }}$ ed. Baltimore: Lippincott Williams \& Wilkins; 1997. p. 87-118.

17. Arora S, Tewari S. The morphology of the apical foramen in posterior teeth in a North Indian population. Int Endod J 2009;42:930-9.
18. Nasseri M, Ahangari Z, Momayyez M. Evaluation of the distance of apical constriction from anatomic and radiographic apices in extracted maxillary second premolars using the clearing technique. J Dent Sch Shahid Beheshti Univ Med Sci 2012;30:95-9.

19. Marroquín BB, El-Sayed MA, Willershausen-Zönnchen B. Morphology of the physiological foramen: I. Maxillary and mandibular molars. J Endod 2004;30:321-8.

20. Stein TJ, Corcoran JF. Nonionizing method of locating the apical constriction (minor foramen) in root canals. Oral Surg Oral Med Oral Pathol 1991;71:96-9.

21. Piasecki L, Carneiro E, da Silva Neto UX, Westphalen VP, Brandão CG, Gambarini G, et al. The use of micro-computed tomography to determine the accuracy of 2 electronic apex locators and anatomic variations affecting their precision. J Endod 2016;42:1263-7.

22. Hassanien EE, Hashem A, Chalfin H. Histomorphometric study of the root apex of mandibular premolar teeth: An attempt to correlate working length measured with electronic and radiograph methods to various anatomic positions in the apical portion of the canal. J Endod 2008;34:408-12

23. Kim E, Lee SJ. Electronic apex locator. Dent Clin North Am 2004:48:35-54. 